\title{
Depletion of Plasma Gelsolin in Patients with Tick-Borne Encephalitis and Lyme Neuroborreliosis
}

\author{
Alina Kułakowska ${ }^{a}$ Joanna M. Zajkowska ${ }^{b}$ Nicholas J. Ciccarellid \\ Barbara Mroczko ${ }^{c}$ Wiesław Drozdowski ${ }^{a}$ Robert Bucki ${ }^{d}$ \\ Departments of a Neurology, ${ }^{b}$ Infectious Diseases and Neuroinfections and ${ }^{\mathrm{c} B i o c h e m i c a l ~ D i a g n o s t i c s, ~ M e d i c a l ~}$

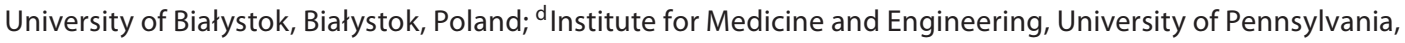 \\ Philadelphia, Pa., USA
}

\section{Key Words}

Plasma gelsolin • Cerebrospinal fluid · Tick-borne

encephalitis $\cdot$ Lyme disease

\begin{abstract}
Background/Aims: Cell damage during the course of inflammation results in cytoplasmic actin release, which if not eliminated by the extracellular actin scavenger system, composed of gelsolin and vitamin D binding protein, can cause dysfunction of hemostasis and toxicity towards surrounding cells. In this study, we test the hypothesis that an inflammatory reaction induced by central nervous system infections such as tick-borne encephalitis (TBE) or Lyme neuroborreliosis (LNB) will result in plasma gelsolin concentration changes in the blood and cerebrospinal fluid (CSF). Methods: Quantitative Western blot was used to determine gelsolin levels in 58 samples, which include: 29 patients without infection (diagnosed with conditions such as idiopathic cephalalgia, idiopathic Bell's facial nerve palsy and ischialgia due to discopathy in which standard CSF diagnostic tests show no abnormalities), 12 patients diagnosed with TBE, and 17 patients diagnosed with LNB sub forma meningitis. Results and Conclusion: The gelsolin concentration in the blood of patients
\end{abstract}

\section{KARGER}

Fax +41613061234

E-Mail karger@karger.ch

www.karger.com (c) 2011 S. Karger AG, Basel

Accessible online at: www.karger.com/ndd with TBE $(163.2 \pm 80.8 \mu \mathrm{g} / \mathrm{ml})$ and LNB $(113.6 \pm 56.8 \mu \mathrm{g} / \mathrm{ml})$ was significantly lower ( $<<0.05$ and $p<0.001$, respectively) compared to the control group $(226.3 \pm 100.7 \mu \mathrm{g} / \mathrm{ml})$. Furthermore, there was no statistically significant difference between the CSF gelsolin concentration in patients with TBE $(3.9 \pm 3.3 \mu \mathrm{g} / \mathrm{ml}), \operatorname{LNB}(2.9 \pm 1.2 \mu \mathrm{g} / \mathrm{ml})$ and the control group $(3.7 \pm 3.3 \mu \mathrm{g} / \mathrm{ml})$. An observed decrease in gelsolin concentration in the blood of TBE and LNB patients supports previous findings indicating the involvement of gelsolin in the pathophysiology of an inflammatory response. Therefore, evaluation of blood gelsolin concentration and administration of recombinant plasma gelsolin might provide a new tool to develop diagnostic and therapeutic strategies for TBE and LNB.

Copyright $\odot 2011$ S. Karger AG, Basel

Plasma gelsolin is a multifunctional protein present in the extracellular environment that has the ability to bind actin and various bioactive lipids such as lysophosphatidic acid, platelet-activating factor [1], sphingosine-1phosphate [2] and bacterial lipopolysaccharides [3]. Binding of these inflammatory mediators to gelsolin decreases its ability to sever actin filaments, and could 
Table 1. Clinical and laboratory characteristics of the patient groups

\begin{tabular}{|c|c|c|c|c|c|}
\hline \multirow[t]{2}{*}{ Clinical group } & \multirow{2}{*}{$\begin{array}{l}\text { Total } \\
\text { number }\end{array}$} & \multirow{2}{*}{$\begin{array}{l}\text { Age } \\
\text { years }\end{array}$} & \multicolumn{3}{|l|}{ CSF } \\
\hline & & & $\mathrm{Q}(\mathrm{Alb})$ & $\begin{array}{l}\text { total protein } \\
\mu \mathrm{g} / \mathrm{ml}\end{array}$ & lymphocytes \\
\hline LNB & $17(7)$ & $48.5 \pm 10.5$ & $9.6 \pm 0.9$ & $782 \pm 152$ & $48.2 \pm 9.3$ \\
\hline TBE & $12(5)$ & $51.2 \pm 23.4$ & $11.2 \pm 1.3$ & $879 \pm 163$ & $114 \pm 10.6$ \\
\hline \multicolumn{6}{|l|}{ Control } \\
\hline Idiopathic cephalalgia & $16(11)$ & $47.3 \pm 25.3$ & $6.9 \pm 1.4$ & $401 \pm 165$ & $3.1 \pm 2.1$ \\
\hline Idiopathic Bell's facial nerve palsy & $11(5)$ & $52.2 \pm 18.6$ & $7.2 \pm 0.8$ & $360 \pm 182$ & $5.3 \pm 2.2$ \\
\hline Ischialgia due to discopathy & $2(0)$ & $45.1 \pm 26.2$ & $6.8 \pm 1.8$ & $391 \pm 192$ & $4.2 \pm 1.1$ \\
\hline
\end{tabular}

Figures in parentheses are numbers of females. $\mathrm{Q}(\mathrm{Alb})=$ Albumin quotient.

potentially result in dysfunction of the blood actin scavenger system. A similar disorder may be expected when plasma gelsolin levels decrease. The lack of ability to eliminate F-actin from circulation (independently of its cause) could result in secondary tissue injury development. Indeed, a decrease in blood gelsolin concentration was found to correlate with adverse occurrences in critically ill patients [4], whereas gelsolin administration decreases mortality in experimental sepsis in animal models [5]. Several studies indicate that plasma gelsolin, aside from scavenging F-actin, may function as a buffer for bioactive lipids, preventing tissue injuries caused by inflammatory mediators $[1,6-9]$. Therefore, by preventing Factin accumulation and modulating cellular response to bioactive lipids, gelsolin is potentially involved in the regulation of the host inflammatory response.

Tick-borne encephalitis (TBE) and Lyme neuroborreliosis (LNB) represent etiologically different neurological manifestations of systemic infection with TBE virus and the spirochete Borrelia burgdorferi, respectively [10]. Both can pose a diagnostic and therapeutic challenge for practicing neurologists since no test is definitively specific for LNB, and many TBE symptoms mimic those of several other central nervous system (CNS) diseases [11, 12]. TBE leads to the development of meningitis or encephalitis, which is characterized by swelling of the brain due to inflammation [13]. Although TBE is most commonly recognized as a neurologic disease, mild febrile illnesses can also occur and long-lasting or permanent neuropsychiatric sequelae are observed in $10-20 \%$ of infected patients. Cellular and humoral pathways of the immune system, especially granzyme B-releasing cytotoxic $T$ cells and macrophages/microglia, mainly contribute to tissue destruction in TBE [14]. In the course of LNB, the process of inflammation is primarily localized to dorsal root ganglia, nerve roots and leptomeninges. Similar to TBE, T lymphocytes were identified as the predominant inflammatory cell marker found in CNS tissue of subjects with LNB. They are accompanied by significantly increased amounts of immunoglobulin (IgG, IgM) and complement (C1q). Usually, LNB manifests as meningitis, from time to time accompanied with radiculitis. No specific treatment is currently known for TBE, but this disease can be prevented by active immunization [15]. On the other hand, antibiotic therapy is the treatment of choice for LNB. By analogy with other CNS conditions with inflammatory components, we hypothesize that in the case of TBE and LNB, blocking inflammatory responses at sites of infection might provide a new treatment strategy.

\section{Materials and Methods}

\section{Specimen Collections}

Human blood and cerebrospinal fluid (CSF) specimen collection was performed in the Department of Neurology and Department of Infectious Diseases and Neuroinfections at the Medical University of Białystok. The protocol for this study was approved by the Ethics Committee for Research on Humans (Medical University of Białystok). At the time of patient recruitment, written consent was obtained from all subjects. All individuals were undergoing lumbar puncture for diagnostic purposes and CSF evaluation was an isolated event. Shortly after collection, samples of $\mathrm{CSF}$ and blood were centrifuged $(2000 \mathrm{~g}, 10 \mathrm{~min})$ and the supernatants of CSF and blood plasma were frozen. Clinical and laboratory characteristics of the patient groups are given in table 1. TBE was confirmed by detection of anti-TBE virus antibodies in serum and CSF by ELISA (Virion-Serion kit). LNB was diagnosed according to the European Federation of Neurological Societies criteria and in all our patients the diagnosis was 'definite neu- 
roborreliosis' [16]. ELISA (Biomedica kit) and immunoblotting (LINE Virotech) were used to detect antibodies against B. burgdorferi in serum and CSF of LNB patients. Since Bell's palsy may have an infectious origin, we would like to emphasize that all patients included in our control group diagnosed with Bell's palsy suffered from its idiopathic form. Additionally, none were immunocompromised, and, with an ELISA kit, all were shown to lack herpes simplex virus 1 antibodies in their blood (ELISA kit; Genzyme Virotech GmbH, Rüsselsheim, Germany).

\section{Quantitative Immunoblotting}

Plasma and CSF samples were boiled in the presence of sample buffer for $10 \mathrm{~min}$ and subjected to electrophoresis with $10 \%$ sodium dodecyl sulfate polyacrylamide. Samples loaded in each gel were accompanied by recombinant human plasma gelsolin standard (loaded in a concentration range comparable to the gelsolin concentration in the samples). After electrophoresis, proteins were transferred to polyvinylidene fluoride membranes (Amersham Biosciences, Little Chalfont, UK). The membrane was then blocked by incubation in $5 \%(\mathrm{w} / \mathrm{v})$ nonfat dry milk dissolved in TBS-T (150 mM NaCl, $50 \mathrm{~mm}$ Tris, 0.05\% Tween 20, $\mathrm{pH}=7.4$ ). Transferred proteins were probed with a monoclonal antihuman gelsolin antibody (Sigma, St. Louis, Mo., USA) used at a 1:10,000 dilution in TBS-T. After incubation with horseradish-peroxidaseconjugated secondary antibodies (1:20,000 dilution), immunoblots were developed with a Fuji Film LAS-300 system using an ECL Plus HRP-targeted chemiluminescent substrate (Amersham Biosciences, Little Chalfont, UK). Western blots were quantified with densitometric analysis (Image Gauge - version 4.22 software; Fuji Photo Film Co., USA). The standard curve for determination of gelsolin concentration was prepared using gelsolin concentrations at 5, 7.5, 10, 15, 20 and $30 \mathrm{ng}$. The intensity of each band on the Western blot minus the background signal was plotted versus the known amount of gelsolin and fitted to a straight line $(r \geq 0.9)$, the graph was used as a standard curve to determine unknown gelsolin levels in simultaneously assayed patient samples [17].

\section{Statistical Analysis}

Data are reported as means \pm SD. Differences between means were evaluated using the unpaired Student's t test, with $\mathrm{p}<0.05$ being taken as the level of significance. Pearson's correlation test was used to compare values of gelsolin concentration in blood and CSF.

\section{Results}

\section{Gelsolin Levels in Blood}

Quantitative Western blot analysis reveals a significantly lower gelsolin concentration in the blood of TBE $(p<0.05)$ and LNB $(p<0.001)$ subjects compared to the gelsolin concentration in the control group (fig. 1a). In blood samples from patients diagnosed with TBE and LNB, gelsolin levels were in a range between 84-298 and 15-193 $\mu \mathrm{g} / \mathrm{ml}$, respectively. On average, the gelsolin concentration in the blood of control, TBE and LNB patients was equal to 226,163 and $113 \mu \mathrm{g} / \mathrm{ml}$, respectively.

Plasma Gelsolin in the Blood of TBE and LNB Patients

\section{Gelsolin Levels in CSF}

In our previous study [8], with the use of a specific antibody against a secreted isoform of gelsolin, we have shown that gelsolin present in CSF consists predominantly of its plasma isoform. Here we report that the gelsolin concentration in CSF, collected from patients diagnosed with TBE $(3.9 \pm 3.3 \mu \mathrm{g} / \mathrm{ml}), \operatorname{LNB}(2.9 \pm 1.2 \mu \mathrm{g} /$ $\mathrm{ml})$ and the control group $(3.7 \pm 3.3 \mu \mathrm{g} / \mathrm{ml})$, did not significantly differ (fig. 1b). The analysis using Pearson's test indicated a correlation between gelsolin levels in CSF and blood in patients suffering from TBE, but not in those suffering from LNB. This result suggests that dysfunction of the blood-CSF barrier might be more severe in the course of LNB.

\section{Discussion}

Previously observed decreases in blood gelsolin levels in different medical conditions associated with an inflammatory response or parenchymal tissue damage indicate that this protein might function as a regulator of the innate immune response $[5,9,17]$. In agreement with those previous studies we found that 2 etiopathologically different infections affecting the CNS, such as LNB and TBE (caused by bacterial and viral pathogens, respectively) lead to alteration of gelsolin levels in blood. More precisely, our study reveals an approximately $20-50 \%$ lower blood gelsolin concentration in LNB and TBE patients compared to control subjects. However, the cause of the lower blood gelsolin levels is unclear, and at this point it is only possible to provide a hypothetical explanation. Firstly, it is possible that axonal damage with actin release within the intrathecal compartment, which takes place in CNS tissue during LNB or TBE development, may increase a demand for gelsolin that results in its depletion from the blood [18]. Such an increased demand would account for the decrease in gelsolin in the blood, assuming that normal blood levels cannot be maintained by increased production, which in the case of plasma gelsolin occurs mainly in muscle cells [19]. Secondly, it can be hypothesized that neuronal release of actin within the CNS will cause mobilization and accumulation of gelsolin in the CNS. An increase in CSF gelsolin levels may also be expected due to blood-CSF barrier dysfunction, which usually accompanies LNB and TBE [20, 21]. However, the latter possibility is less likely since we did not observe significantly higher intrathecal levels of gelsolin in the CSF of LNB and TBE patients, as could be expected, based on the gelsolin concentration gradient between blood and 

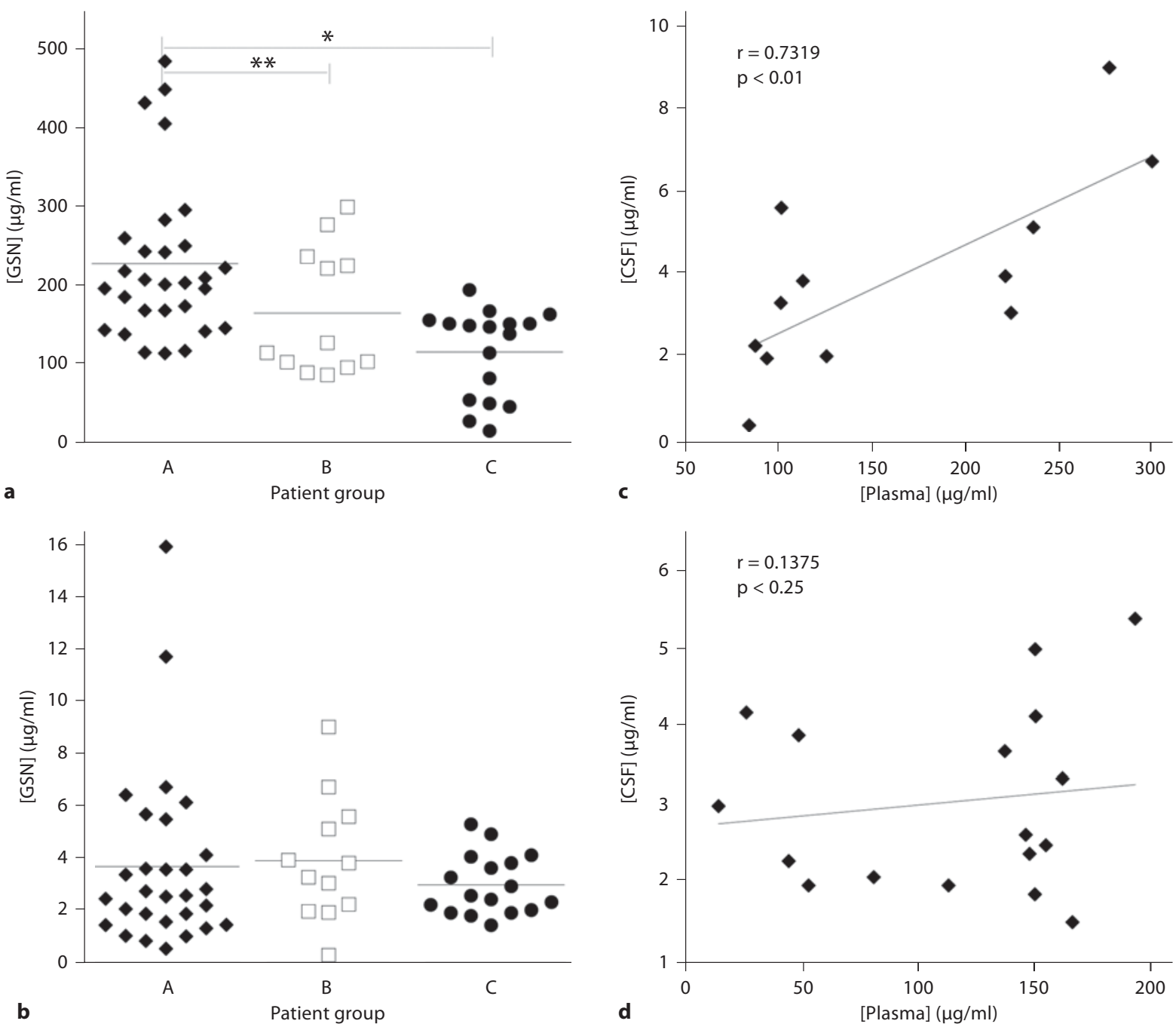

Fig. 1. Gelsolin concentration (GSN) in blood (a) and CSF (b) collected from A - control patients, B - patients diagnosed with TBE and $\mathrm{C}-$ patients diagnosed with LNB. Horizontal bars depict means. ${ }^{*} \mathrm{p}<0.001,{ }^{* *} \mathrm{p}<$ 0.05 compared to gelsolin blood concentration in the control group. Correlation between the blood and CSF levels of gelsolin in patients diagnosed with TBE (c) and patients diagnosed with LNB (d).

CSF. However, the fact that diagnostic lumbar puncture was performed at an early stage of the disease, which usually is not accompanied by severe disruption of the bloodCSF barrier [20,21], and the possibility that gelsolin-Factin complexes might be lost during centrifugation to prepare CSF samples could both impair the interpretation of the data.

Despite being of completely different etiology (bacteria vs. RNA virus), the changes in blood and CSF gelsolin concentrations in LNB and TBE patients were similar. This finding suggests that some common mechanisms engaged in an inflammatory process are responsible for the gelsolin depletion. The innate immune system response, composed of various cell types sharing antigen recognition ability, which is the earliest defence against all pathogens, may provide a molecular basis for the observed gelsolin decrease $[22,23]$. Because of the similarity between multiple sclerosis and LNB chronic inflam- 
mation, it might be expected that the same molecular mechanism is responsible for blood gelsolin depletion in multiple sclerosis and LNB patients $[8,24]$. Since there is a great variety of innate immune molecular factors, it is difficult to establish which ones are responsible for this reaction $[11,25]$. Therefore, plasma gelsolin should be considered a marker of inflammation due to its observed decrease in various conditions associated with tissue injury not limited to infectious causes [26-29].

Our findings are also in agreement with previous suggestions concerning gelsolin function. Gelsolin is a multifunctional protein that can bind various bioactive lipids and influence an immunological host response to serious injury. Gelsolin binds not only eukaryotic, but also prokaryotic lipids of Gram-positive and Gram-negative bacteria $[3,30]$. Biologically active phospholipids are an important component of the spirochete B. burgdorferi outer membrane, which contains a lipopolysaccharide-like substance that could potentially interact with gelsolin [11, 31]. On the other hand, the pathogen causing TBE is an enveloped virus (Flaviviridae family) with an RNA genome that does not contain any known active phospholipids. In all cases of CNS infections, independent of their etiology, an array of inflammatory mediators is produced, including platelet-activating factor and sphingosine-1-phosphate [1]. Both of these have a number of proinflammatory properties and are implicated in the pathogenesis of a number of diseases, ranging from an allergic reaction to neurodegenerative disorders such as multiple sclerosis [8].
Our findings, which indicate depletion of gelsolin as a step in the pathophysiology of an inflammatory response to $B$. burgdorferi and TBE virus infections, suggest that administration of recombinant plasma gelsolin warrants consideration as a new therapeutic strategy for these diseases. Further long-term studies are required to evaluate the prognostic value of gelsolin level analysis as a biochemical marker for predicting and monitoring neurological decline in the course of LNB and TBE. It is possible that gelsolin evaluation in combination with other biomarkers can increase diagnostic accuracy and better assessment of CNS infections.

\section{Acknowledgements}

We thank Dr. P. Janmey (University of Pennsylvania) for critical reading, Dr. Q. Wen (University of Pennsylvania) for help with statistical analysis. This work was supported by NIH grant HL067286 and the Medical University of Bialystok, grant 3-44668L.

\section{Disclosure Statement}

In 2008, R.B. was involved in a sponsored research agreement with Critical Biologics Inc. in a project directed at evaluating the potential clinical use of gelsolin, but not otherwise related to the present study. None of the research reported in this paper was supported by any corporate entity. The other authors have no conflict of interest to declare.

\section{References}

1 Osborn TM, Dahlgren C, Hartwig JH, Stossel TP: Modifications of cellular responses to lysophosphatidic acid and platelet-activating factor by plasma gelsolin. Am J Physiol Cell Physiol 2007;292:C1323-C1330.

-2 Bucki R, Kulakowska A, Byfield FJ, Zendzian-Piotrowska M, Baranowski M, Marzec M, Winer JP, Ciccarelli NJ, Gorski J, Drozdowski W, Bittman R, Janmey PA: Plasma gelsolin modulates cellular response to sphingosine-1-phosphate. Am J Physiol Cell Physiol 2010;299:C1516-C1523.

-3 Bucki R, Georges PC, Espinassous Q, Funaki M, Pastore JJ, Chaby R, Janmey PA: Inactivation of endotoxin by human plasma gelsolin. Biochemistry 2005;44:9590-9597.
4 DiNubile MJ, Stossel TP, Ljunghusen OC, Ferrara JL, Antin JH: Prognostic implications of declining plasma gelsolin levels after allogeneic stem cell transplantation. Blood 2002;100:4367-4371.

5 Lee PS, Waxman AB, Cotich KL, Chung SW, Perrella MA, Stossel TP: Plasma gelsolin is a marker and therapeutic agent in animal sepsis. Crit Care Med 2007;35:849-855.

6 Rothenbach PA, Dahl B, Schwartz JJ, O'Keefe GE, Yamamoto M, Lee WM, Horton JW, Yin HL, Turnage RH: Recombinant plasma gelsolin infusion attenuates burn-induced pulmonary microvascular dysfunction. J Appl Physiol 2004;96:25-31.

7 Lee PS, Patel SR, Christiani DC, Bajwa E, Stossel TP, Waxman AB: Plasma gelsolin depletion and circulating actin in sepsis: a pilot study. PLoS One 2008;3:e3712.
8 Kulakowska A, Drozdowski W, Sadzynski A, Bucki R, Janmey PA: Gelsolin concentration in cerebrospinal fluid from patients with multiple sclerosis and other neurological disorders. Eur J Neurol 2008;15:584-588.

9 Lee PS, Sampath K, Karumanchi SA, Tamez $\mathrm{H}$, Bhan I, Isakova T, Gutierrez OM, Wolf M, Chang Y, Stossel TP, Thadhani R: Plasma gelsolin and circulating actin correlate with hemodialysis mortality. J Am Soc Nephrol 2009;20:1140-1148.

10 Hildenbrand P, Craven DE, Jones R, Nemeskal P: Lyme neuroborreliosis: manifestations of a rapidly emerging zoonosis. AJNR Am J Neuroradiol 2009;30:1079-1087.

-11 Pachner AR, Steiner I: Lyme neuroborreliosis: infection, immunity, and inflammation. Lancet Neurol 2007;6:544-552. 
12 Fallon BA, Levin ES, Schweitzer PJ, Hardesty D: Inflammation and central nervous system Lyme disease. Neurobiol Dis 2010;37: 534-541.

-13 Atrasheuskaya AV, Fredeking TM, Ignatyev GM: Changes in immune parameters and their correction in human cases of tickborne encephalitis. Clin Exp Immunol 2003; 131:148-154.

14 Gelpi E, Preusser M, Laggner U, Garzuly F Holzmann H, Heinz FX, Budka H: Inflammatory response in human tick-borne encephalitis: analysis of postmortem brain tissue. J Neurovirol 2006;12:322-327.

15 Kaiser R: Tick-borne encephalitis. Infect Dis Clin North Am 2008;22:561-575, x.

16 Mygland A, Ljostad U, Fingerle V, Rupprecht T, Schmutzhard E, Steiner I: EFNS guidelines on the diagnosis and management of European Lyme neuroborreliosis. Eur J Neurol 2010;17:8-16, e11-e14.

-17 Mounzer KC, Moncure M, Smith YR, DiNubile MJ: Relationship of admission plasma gelsolin levels to clinical outcomes in patients after major trauma. Am J Respir Crit Care Med 1999;160:1673-1681.

18 Nau R, Christen HJ, Eiffert H: Lyme disease - current state of knowledge. Dtsch Arztebl Int 2009;106:72-81, quiz 82, I.
19 Kwiatkowski DJ, Mehl R, Izumo S, NadalGinard B, Yin HL: Muscle is the major source of plasma gelsolin. J Biol Chem 1988;263: 8239-8243.

20 Mansfield KL, Johnson N, Phipps LP, Stephenson JR, Fooks AR, Solomon T: Tickborne encephalitis virus - a review of an emerging zoonosis. J Gen Virol 2009;90: 1781-1794.

21 Neuwelt EA: Mechanisms of disease: the blood-brain barrier. Neurosurgery 2004;54: 131-140, discussion 141-132.

22 Lipscomb MF, Masten BJ: Dendritic cells: immune regulators in health and disease. Physiol Rev 2002;82:97-130.

23 Moretta A, Marcenaro E, Parolini S, Ferlazzo G, Moretta L: NK cells at the interface between innate and adaptive immunity. Cell Death Differ 2008;15:226-233.

24 Aravalli RN, Peterson PK, Lokensgard JR: Toll-like receptors in defense and damage of the central nervous system. J Neuroimmune Pharmacol 2007;2:297-312.

25 Bucki R, Levental I, Kulakowska A, Janmey PA: Plasma gelsolin: function, prognostic value, and potential therapeutic use. Curr Protein Pept Sci 2008;9:541-551.

26 Smith DB, Janmey PA, Lind SE: Circulating actin-gelsolin complexes following oleic acid-induced lung injury. Am J Pathol 1988; 130:261-267.
27 Lind SE, Smith DB, Janmey PA, Stossel TP: Depression of gelsolin levels and detection of gelsolin-actin complexes in plasma of patients with acute lung injury. Am Rev Respir Dis 1988;138:429-434.

28 Suhler E, Lin W, Yin HL, Lee WM: Decreased plasma gelsolin concentrations in acute liver failure, myocardial infarction, septic shock, and myonecrosis. Crit Care Med 1997;25:594-598.

29 Osborn TM, Verdrengh M, Stossel TP, Tarkowski A, Bokarewa M: Decreased levels of the gelsolin plasma isoform in patients with rheumatoid arthritis. Arthritis Res Ther 2008; 10:R117.

30 Bucki R, Byfield FJ, Kulakowska A, McCormick ME, Drozdowski W, Namiot Z, Hartung T, Janmey PA: Extracellular gelsolin binds lipoteichoic acid and modulates cellular response to proinflammatory bacterial wall components. J Immunol 2008; 181: 4936-4944.

-31 Cinco M: Selection of a Borrelia burgdorferi antigenic variant by cultivation in the presence of increasing amounts of homologous immune serum. FEMS Microbiol Lett 1992; 71:15-18. 